\title{
Pendidikan Politik Melalui Pembelajaran Pendidikan Kewarganegaraan untuk Meningkatkan Kesadaran Politik Siswa
}

\author{
Yohanes Berkhmas Mulyadi ${ }^{\text {** }}$, Anyan ${ }^{2}$ \\ ${ }^{a}$ STKIP Persada Khatulistiwa Sintang Indonesia \\ ${ }^{1}$ yostellano@gmail.com* ${ }^{*}{ }^{2}$ anyanright@gmail.com \\ *korespondensi penulis
}

\section{Informasi artikel}

Received :

August 26, 2018.

Revised :

September 08,2018.

Publish :

January 01, 2019.

Kata kunci:

Pendidikan Politik

Pembelajaran PKn

Kesadaran Politik

\section{Keywords:}

Political education

Student learning,

Student political

awareness

\begin{abstract}
ABSTRAK
Tujuan penelitian ini untuk mendeskripsikan pendidikan politik melalui pembelajaran pendidikan kewarganegaraan untuk meningkatkan kesadaran politik siswa SMA kelas X, XI, XII. Jenis penelitian ini adalah deskriptif, dengan pendekatan kualitatif. Subjek penelitian ditentukan dengan teknik purposive sampling. Subjek penelitian ini terdiri dari Kepala Sekolah, Guru Wali Kelas, Kepala bagian Kemahasiswaan, Guru Mata Pelajaran PKn,Pembina OSIS, Ketua OSIS dan anggota Pramuka. Pengumpulan data dalam penelitian ini dilakukan dengan observasi, wawancara mendalam dan dokumentasi.Teknik analisis data dilakukan dengan reduksi data, kategorisasi, display/penyajian, dan pengambilan kesimpulan. Hasil penelitian ini menunjukkan bahwa untuk meningkatkan kesadaran politik siswa, dibutuhkan pendidikan politik melalui pembelajaran Pendidikan Kewarganegaraan. Bentuk pendidikan politik melalui pembelajaran Pendidikan Kewarganegaraan di kelas adalah bermain peran, diskusi, pembelajaran berbagai sumber.Manfaat penelitian ini adalah meningkatnya kesadaran politik siswa yang terekspresi dalam sikap, perbuatan yang baik, kritis dan bertanggungjawab dalam melaksanakan kegiatan sekolah.
\end{abstract}

\begin{abstract}
The purpose of this research is to describe political education through learning civic education to increase the political awareness of high school students of class X, XI, XII. This type of research is descriptive, with a qualitative approach. Research subjects were determined by purposive sampling technique. The subject of this study consisted of the Principal, Classroom Teacher, Head of student affairs, PKn Subject Teacher,Tutor OSIS Teacher, OSIS Chairman and member of Pramuka. Data collection in this study was carried out by observation, indepth interviews and documentation. Data analysis techniques were carried out by data reduction, categorization, display / presentation, and conclusion. The results of this study indicate that to increase students' political awareness, political education is needed through civic education learning. The form of political education through Civics learning in the classroom is role playing, discussion, learning various sources. The benefits of this research are the increased political awareness of students expressed in attitude, good deeds, critical and responsible in carrying out school activities.
\end{abstract}

Copyright (C) 2019 (Yohanes Berkhmas Mulyadi ${ }^{*}$, Anyan $\left.^{2}\right)$. All Right Reserved

How to Cite: Mulyadi, Y., \& Anyan, A. (2019). Pendidikan Politik Melalui Pembelajaran Pendidikan Kewarganegaraan untuk Meningkatkan Kesadaran Politik Siswa. Jurnal Inspirasi Pendidikan, 9(1), 33-38. 


\section{Pendahuluan}

Pendidikan politik dan Pendidikan kewarganegaraan (PKn) di sekolah berguna mengantarkan peserta didik untuk menjadi warga negara yang baik. Sapriya (2013) warga negara yang baik adalah warga negara yang sadar akan hak dan kewajibannya dan mampu melaksanakan semua hak beserta kewajibannya secara sukarela, baik dalam lingkup keluarga, sekolah, masyarakat, dan ikut bertanggung jawab bagi keberlangsungan kehidupan bangsa dan negaranya demi mewujudkan persatuan dan kesatuan bangsa yang Bhinneka Tunggal Ika dalam bingkai Negara Kesatuan Republik Indonesia. Rohani (2017) menyatakan PKn itu sendiri ingin mewujudkan manusia Indonesia yang seutuhnya yakni manusia yang bertanggung jawab, berbudi pekerti, berakhlak mulia, mempunyai kecerdasan intelektual, emosional, kreatif dan inovatif dalam berbagai bidang kehidupan guna meningkatkan daya saing global. Menurut Kemendiknas (2017) PKn adalah mata pelajaran yang memfokuskan pada pembentukan warga negara yang memahami dan mampu melaksanakan hak-hak dan kewajibannya untuk menjadi warga negara Indonesia yang cerdas, terampil, berkarakter yang diamanatkan oleh Pancasila dan Undang-Undang Dasar 1945.

Rahayu \& Suryaningsih (2016) menyatakan PKn di Sekolah Menengah Atas (SMA) adalah usaha membekali peserta didik dengan pengetahuan dan kemampuan dasar yang berkenaan dengan politik, moral dan hubungan antar warga negara, dengan tujuan supaya siswa-siswi dapat memahami tentang politik dan sistem politik di Indonesia serta mampu menjadi warga negara yang bekerja untuk pembangunan bangsa dan negara. Dalam konteks kesadaran politik siswa, Nasution (2012) menyatakan pendidikan politik di sekolah merupakan salah satu wahana untuk mengantarkan siswa sebagai warga negara memahami politik, melaksanakan hak dan kewajiban politiknya demi kepentingan bersama. Kantaprawira (2014) pendidikan politik adalah bagian dari pengajaran politik merupakan usaha membekali siswa dengan ilmu politik dalam arti untuk mencerdaskan kehidupan politik siswa dan meningkatkan kesadaran siswa dalam kehidupan berpolitik guna menunjang kelestarian Pancasila dan Undang-Undang Dasar 1945 sebagai budaya politik bangsa. Jika dihubungkan dengan sekolah sebagai lembaga pendidikan maka pendidikan politik di sekolah adalah proses pembelajaran dan pemahaman tentang hak dan kewajiban serta tanggungjawab setiap peserta didik, agar memiliki kesadaran politik yang berdampak pada partisipasi politik (Nataraharja, 2012).

Kartono (2009) pendidikan politik di sekolah melalui pembelajaran PKn adalah mengajarkan manusia untuk mampu mengembangkan bakat dan kemampuan kognitif, afektif, maupun psikomotorik yang ada dalam setiap individu supaya bisa berpartisipasi aktif dalam setiap kegiatan politik dan menciptakan generasi muda yang sadar akan kehidupan berbangsa dan bernegara berdasarkan Pancasila dan Undang-Undang Dasar 1945. Fajar (2010) pendidikan politik melalui pembelajaran PKn (citizenship education) dilaksanakan untuk mengembangkan warga negara yang cerdas dan baik untuk semua jalur dan jenjang pendidikan termasuk kecerdasan politik siswa perlu ditumbuhkembangkan sebagai bagian persiapan untuk melaksanakan kegiatan politik di kemudian harinya. Djahiri (2006) pendidikan politik melalui pembelajaran PKn adalah suatu proses penanaman nilai-nilai moral politik pada peserta didik dan nilai-nilai moral politik tersebut terintegrasi dalam ideologi Pancasila yaitu Ketuhanan, Kemanusiaan, Persatuan, Kerakyatan dan Keadilan Sosial. Hermawan (2007) pendidikan politik melalui pembelajaran PKn pada siswa adalah bentuk pengajaran politik agar dapat menjadi warga negara yang mampu bersikap, berbuat dan bertanggung jawab dalam bidang politik,khususnya mampu menerapkan norma moral politik dalam kehidupan harian di sekolah, rumah dan masyarakat, juga membentuk manusia yang 
Jurnal Inspirasi Pendidikan, VOL.9, NO.1, Edisi Januari 2019 Pendidikan Politik Melalui Pembelajaran Pendidikan Kewarganegaraan untuk Meningkatkan Kesadaran Politik Siswa

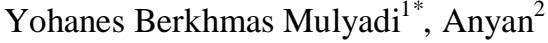
Hal: $33-38$

beriman dan bertakwa, memiliki pengetahuan yang luas, cinta tanah air, berbudi luhur, memelihara persatuan dan kesatuan bangsa, berpartisipasi dalam mensukseskan pembangunan bangsa.

Tujuan pendidikan politik melalui pembelajaran PKn di SMA Negeri 1 Kelam Permai, menurut Darmawan (2013) adalah supaya siswa-siswi memahami tentang politik, mengetahui proses politik dan pada saat berusia 17 tahun dapat melaksanakan kegiatan politik seperti mengikuti pemilihan umum legislatif dan eksekutif, membentuk kesadaran siswa sebagai warga negara yang sadar akan dinamika politik kenegaraan. Wardani, (2018) tujuan pendidikan politik di sekolah yaitu siswa-siswi memiliki kesiapan untuk berpartisipasi dalam kehidupan politik berlandaskan pada nilai-nilai Pancasila dan Undang-Undang Dasar NRI 1945. Nataraharja (2012) mempertegas tujuan pendidikan politik melalui pembelajaran PKn di SMA adalah membentuk kompetensi kewarganegaraan siswa, yang terdiri dari civic knowlegde (pengetahuan kewarganegaraan), dan civic skills (kecakapan berpikir kritis, rasional, kreatif dan siswa), kecakapan berpartisipasi dan bertanggungjawab dalam kehidupan bermasyarakat, berbangsa, dan bernegara. Suharyanto, A. (2016) tujuan pendidikan politik di sekolah melalui pembelajaran PKn adalah membentuk perilaku politik siswa yang diwujudnyatakan dalam kehidupan sehari-hari, melatih siswa-siswi menjadi warga negara yang baik yaitu dapat menjalankan fungsi politik seperti kerjasama, bermusyawarah, toleran dan loyal terhadap bangsa dan negara, ,mengembangkan semua bakat dan kemampuan siswa seperti aspek kognitif, kritis, sikap positif, keterampilan politik, dan membuat peserta didik berani bertanggungjawab serta giat dalam belajar demi mencapai masa depannya.

Permasalahan pendidikan politik melalui pembelajaran PKn di SMA Negeri 1 Kelam Permai, adalah kurangnya pengembangan pembelajaran PKn yang berorientasi pada kecerdasan politik, kurangnya media, sumber dan mekanisme evaluasi atas capaian pembelajaran, kurang berperilaku efektif dan bijak dalam merespons isu-isu publik seperti isu politik yang berkembangan di tanah air, kurangnya kesadaran politik siswa. Permasalahan pendidikan politik melalui pembelajaran PKn di SMA Negeri 1 Kelam Permai tersebut di atas terdapat kekurangan atau kelemahan dalam hal kesadaran politik siswa yang diketahui dari kurang antusias siswa-siswi apabila berbicara tentang politik dan demokrasi di Indonesia, cara berpikir siswa-siswi tentang politik itu adalah kotor atau negatif, kurang menunjukkan sikap dan tanggung jawab siswa-siswi dalam menyikapi isu-isu politik identitas yang berkembang di sekolah dan di masyarakat.Permasalahan ini sesuai dengan penelitian Batawi (2013) mengatakan banyak pemilih pemula yang tidak memilih karena kurangnya kesadaran politiknya.Kesadaran politik penting ditingkatkan supaya dapat memahami politik dan dapat mengikuti kegiatan politik.

Penelitian ini secara umum bertujuan, antara lain meningkatkan kesadaran politik siswa-siswi SMA Negeri 1 Kelam Permai bahwa politik itu adalah sebuah strategi dalam melaksanakan suatu kegiatan politik, mempersiapkan siswa untuk berperan aktif sebagai warga negara, mengembangkan paradigma berpikir yang positif tentang politik, mengembangkan sikap demokratis diantara perbedaan suku, agama, adat dan budaya peserta didik, meningkatkan cara berpikir kritis siswa-siswi terhadap kehadiran media yang terus menerus menyorot isu-isu yang menyimpang dari prinsip-prinsip demokrasi dan janji politisi yang jarang ditepati sehingga menimbulkan pesimisme pada pemilih. Penelitian ini secara khusus bertujuan untuk 1) mendeskripsikan proses pendidikan politik melalui pembelajaran PKn di SMA Negeri 1 Kelam Permai, 2) Mendeskripsikan bentuk pendidikan politik melalui pembelajaran PKn di SMA Negeri 1 Kelam Permai, 3) Mendeskripsikan kesadaran politik siswa melalui pembelajaran PKn di SMA Negeri 1 Kelam Permai. 


\section{Metode}

Penelitian ini menggunakan pendekatan kualitatif (qualitative approach), dengan jenis penelitian adalah deskriptif dan metode yang digunakan dalam penelitian adalah deskriptif analisis, artinya hanya mendeskripsikan pendidikan politik melalui pembelajaran PKn untuk meningkatkan kesadaran politik siswa di SMA Negeri 1 Kelam Permai, Kabupaten Sintang.Tempat atau lokasi penelitian yaitu SMA Negeri 1 Kelam Permai, Jalan Raya Jetak Kecamatan Kelam Kabupaten Sintang, dengan subyek penelitian ditentukan dengan teknik purposive bersifat snowball sampling artinya peneliti menentukan sendiri sampel yang diambil karena pertimbangan tertentu, (Sugiyono, 2012), dan subyek dalam penelitian ini adalah kepala sekolah SMA Negeri 1 Kelam Permai, guru mata pelajaran PKn, guru wali kelas, kepala bagian kesiswaan, pembina OSIS, ketua OSIS dan anggota pramuka. Tahapan pengumpulan data terdiri dari tiga tahap yakni tahap perencanaan, tahap pelaksanaan dan tahap analisis data. Tahap perencanaan dimulai dari mengurus perijinan dan administrasi terkait dengan rencana pelaksanaan penelitian dan tahap pelaksanaan penelitian dimulai dengan menyusun instrumen penelitian berupa panduan observasi, panduan wawancara, dan dokumentasi serta pada tahap pengumpulan data peneliti terjun ke sekolah untuk melakukan observasi,wawancara mendalam dan dokumentasi kepada responden terkait pendidikan politik melalui pembelajaran PKn. Tahap selanjutnya yakni tahap analisis data, setelah selesai proses pengumpulan data diperoleh sejumlah data kualitatif diteruskan dengan analisis dan pengolahan data berpedoman pada data yang terkumpul dari pertanyaan penelitian, dan pada tahapan analisis data ini semua proses analisis data kualitatif dilakukan dalam empat alur kegiatan yang terjadi secara bersamaan, yaitu catatan lapangan, pengumpulan informasi, penyajian informasi, dan penarikan kesimpulan.

\section{Hasil dan pembahasan}

Hasil penelitian pendidikan politik melalui pembelajaran PKn untuk meningkatkan kesadaran politik siswa adalah siswa-siswi dapat mengikuti kegiatan upacara bendera yang dilaksanakan pada hari senin, memperingati Hari Guru Nasional, Hari Pendidikan Nasional, Hari Ulang Tahun Kemerdekaan Republik Indonesia dengan baik. Kegiatan upacara bendera sebagai suatu wahana membentuk rasa nasionalisme, patriotisme dan kedisipilinan siswa. Prajarto (2011) mengatakan bahwa salah satu cara untuk menimbulkan spirit nasionalisme dan patriotisme siswa adalah mengikuti upacara bendera dan menyanyikan lagu-lagu kebangsaan di sekolah dan atau di luar sekolah. Proses pendidikan politik nampak dalam melakukan kegiatan ekstrakurikuler, seperti Pramuka, Palang Merah Remaja (PMR), Organisasi Siswa Intra Sekolah (OSIS). Dalam kegiatan ekstrakurikuler ini, siswa-siswi dibimbing dan dilatih untuk setia dalam menjalankan tugas, bekerja dan berkorban demi kepentingan bersama, menghargai budaya, menjunjung tinggi dan mengaplikasikan nilai-nilai Pancasila dan demokrasi.

Pembelajaran PKn di SMA Negeri 1 Kelam Permai Kabupaten Sintang dilaksanakan secara partisipatif seperti guru dan murid berinteraksi, tanya jawab, siswa-siswi dilatih untuk bermain peran dan diskusi. Bermain peran adalah cara yang dilakukan siswa dalam mengesplorasi nilai-nilai politik dari perspektif siswa. Bermain peran dalam pendidikan politik melalui pembelajaran PKn adalah cara siswa mengeksplorasikan nilai-nilai politik dengan cara mendramatisasikan atau memperagakan dengan tujuan menarik minat, perhatian dan motivasi siswa dalam melaksanakan kegiatan belajar. Bermain peran dengan memerankan tokoh-tokoh politik yang memperjuangkan kepentingan nasional dan 
Jurnal Inspirasi Pendidikan, VOL.9, NO.1, Edisi Januari 2019 Pendidikan Politik Melalui Pembelajaran Pendidikan Kewarganegaraan untuk Meningkatkan Kesadaran Politik Siswa

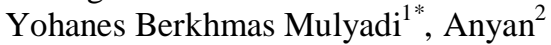
Hal: $33-38$

menghayati nilai- nilai-nilai Pancasila. Diskusi sebagai cara yang tepat bagi siswa untuk mengeksplorasikan aspek masalah dan menemukan solusi atas masalah tersebut sesuai dengan teori, contoh masalah politik identitas dan politik uang yang berkembang di masyarakat menjelang pemilihan umum legislatif dan eksekutif. Diskusi dilakukan secara terorganisir,sistematis dan terstruktur di dalam kelompok kelas. Beberapa materi diskusi PKn sesuai dengan tema antara lain hakekat bangsa, demokrasi, sistem politik Indonesia, budaya politik bangsa,sistem pemerintahan, pemilihan umum. Bermain dan diskusi merupakan salah bentuk pendidikan politik melalui pembelajaran PKn dimana peserta didik diupayakan belajar untuk tampil berbicara dan berkomunikasi di depan umum.

Pendidikan politik melalui pembelajaran PKn di SMA Negeri 1 Kelam Permai adalah siswa-siswi mengikuti sekolah partai dimana partai politik tertentu hadir di SMA Negeri 1 Kelam Permai, masuk ke kelas untuk mengajarkan tentang budaya politik Indonesia. Sekolah partai dilaksanakan pada moment tertentu seperti menjelang pemilu umum legislatif dan eksekutif. Pelaksanaan sekolah partai sangat antusias di kalangan siswa-siswi karena selain mendengar ceramah tentang politik, pemilu dan perkembangan partai politik Indonesia, juga mengetahui politisi yang hadir secara langsung bertemu dengan siswa-siswi. Sekolah partai dari partai politik tertentu adalah usaha untuk membekali peserta didik dengan pengetahuan politik agar mampu memahami politik, dapat melaksanakan hak dan kewajibannya politiknya dan berpartisipasi aktif sebagai warga negara Indonesia yang cerdas, terampil, yang diamanatkan oleh Pancasila dan Undang-Undang dasar 1945, dan mengajak peserta didik untuk memilih calon pemimpin sesuai dengan hati nurani dalam pemilihan umum.

Pendidikan politik melalui pembelajaran PKn di SMA Negeri 1 Kelam Permai memberi manfaat bagi kesadaran politik siswa seperti mereka yang sudah berusia 17 tahun dapat mengikuti pemilihan gubernur dan wakil gubernur Kalimantan Barat 2018, siswa-siswi sebagai pemilih pemula menggunakan hak untuk mengikuti pemilihan umum. Satu suara dalam pemilu merupakan wahana mendukung proses demokratisasi di Indonesia. Kesadaran politik siswa nampak dalam semangat mengikuti ceramah tentang radikalisme dan terorisme yang diberikan oleh pihak kepolisian Sintang, siswa-siswi dapat mengetahui tentang gerakan radikalisme dan terorisme yang berkembang di Indonesia dan harus berpikir kritis serta bijak bila gerakan radikalisme dan terorisme itu masuk dalam wilayah Kalimantan.Kesadaran politik siswa adalah kesadaran akan hak dan kewajiban sebagai warga negara. SMA sebagai pemilih pemula memiliki kesadaran politik dengan berpartisipasi dalam kegiatan politik seperti mengikuti pemilu.

Implikasi penelitian ini terhadap pendidikan politik melalui pembelajaran PKn di sekolah adalah politik sebagai ilmu pengetahuan penting dipahami oleh siswa-siswi para guru terus melakukan pendidikan politik kepada peserta didik supaya mereka bisa memahami tentang politik dan menanggapi secara kritis dan bijak terhadap isu-isu politik yang berkembang di masyarakat. Siswa pun mengaplikasikan nilai-nilai politik sesuai dengan lima sila Pancasila.

\section{Simpulan}

Penelitian tentang pendidikan politik melalui pembelajaran PKn untuk meningkatkan kesadaran politik siswa dapat disimpulkan bahwa siswa-siswi antusias melaksanakan proses pembelajaran PKn yang bertemakan politik. Siswa-siswi semakin sadar akan peran dan tanggung jawab sebagai warga negara yang siap membangun bangsa dan negara Indonesia. Saran peneliti untuk peneliti selanjutnya yaitu kiranya lebih intens mengkaji tentang pendidikan politik di sekolah melalui pembelajaran PKn agar siswa-siswi semakin paham akan politik dan demokrasi Indonesia. 


\section{Referensi}

Bachtiar, F.R. (2014). Pemilu Indonesia: Kiblat Negara Demokrasi dari Berbagai Refresentasi. Jurnal Politik Profetik, 3 (1).

Batawi, J.W.(2013). Tingkat Kesadaran Politik Pemilih Pemula dalam Pilkada Suatu Refleksi School-Based Democracy Education (Studi Kasus Pilkada Kabupaten Halmahera Timur Provinsi Maluku Utara Tahun 2010) Jurnal UNIERA, 2.(2), 26-51.

Darmawan, I. (2013). Analisis Sistem Politik Indonesia. Bandung: Alfabeta.

Djahiri. (2006). Esensi Pendidikan Nilai Moral dan PKn di Era Globalisasi. Bandung : Laboratorium PKn FPIPS UPI

Fajar, W.N. (2010). Model Pendidikan Kewarganegaraan sebagai Media Pendidikn Politik Bagi Kader Partai dalam Meningkatkan Kesadaran Politik.Vol.2, No.1, Desember 2010. Bandung: Sekolah Pascasarjana UPI dan ADSPENSI.

Haryoko. (2009). Efektifitas Pemanfaatan Media Audio Visual Sebagai Alternatif Optimalisasi Model Pembelajaran. Jurnal Edukasi Elektro, 5 (1), 1-10.

Hermawan. (2007). Esensi Pendidikan Politik dan Kaitannya dengan Pembentukkan Warga Negara yang Baik. Jurnal Pendidikan Ilmu Sosial, 15 (29), 26-34.

Kartono, K. (2009). Pendidikan Politik sebagai Bagian Pendidikan Orang Dewasa. Bandung: Mandar Maju.

Kemendiknas. (2017). Buku Guru Pendidikan Pancasila dan Kewarganegaraan. Jakarta : Kemendiknas

Nasution, M.A. (2012). Peranan Parpol dalam Pendidikan Politik dan Wawasan Kebangsaan, Jurnal POLITEIA, 4 (1), 34-40.

Nataraharja, T. (2012). Implementasi Pendidikan Politik Melalui Pembelajaran PKn dalam Mengembangkan Kompetensi Kewarganegaraan. Jurnal Pendidikan 2 (11).

Prajarto, N. (2011). Etika: Keamanan Berpolitik dan Ber-New Media. Jurnal Ilmu Sosial dan Ilmu Politik,14 (3).35-41.

Rahayu \& Suryaningsih. (2016). Pengembangan Model Pembelajaran Pendidikan Politik Berbasis Partisipasi Siswa dalam PKn (Studi pada Siswa SMA Negeri 3 Sukoharjo), Jurnal Ilmiah Pendidikan, Sejarah dan Sosial Budaya. 18 (1).

Rohani. (2017). Pengembangan Bahan Ajar Evaluasi Pengajaran PPKn Untuk Meningkatkan Ranah Afektif Mahasiswa Prodi PPKn IKIP PGRI Pontianak, Jurnal Pendidikan Kewarganegaraan, 7 (2),63-71.

Sapriya. (2013). Konsep Dasar Pendidikan Kewarganegaraan (Edisi Revisi). Bandung:

Universitas Pendidikan Indonesia.

Sugiyono. (2012). Metode Penelitian Pendidikan, Pendekatan Kuantitatif, Kualitatif \& $R \& D$. Bandung: PT. Alfabeta.

Suharyanto, A. (2016). Surat Kabar Sebagai Salah Satu Media Penyampaian Informasi Politik pada Partisipasi Politik Masyarakat, Jurnal Administrasi Publik, 6(2), 123-136.

Wardani, P.S.N. (2018). Partisipasi Politik Pemilih Pemula dalam Pemilihan Umum. Jurnal Pendidikan Ilmu Sosial, 10 (1), 57-62. 